\title{
Cost Estimation of Road Traffic Injuries Among Iranian Motorcyclists Using the Willingness to Pay Method
}

\author{
Elaheh Ainy, ${ }^{1}$ Hamid Soori, ${ }^{1}$ Mojtaba Ganjali, ${ }^{2}$ Behzad Basirat, ${ }^{3}$ and Mashyaneh Haddadi ${ }^{4,}$ \\ ${ }^{1}$ Safety Promotion and Injury Prevention of Shahid Beheshti University of Medical Sciences, Tehran, IR Iran \\ ${ }^{2}$ Statistical Faculty, Shahid Beheshti University, Tehran, IR Iran \\ ${ }^{3}$ Rahvar Research Center of Traffic Police, NAJA, Tehran, IR Iran \\ ${ }^{4}$ Safety Promotion and Injury Prevention Department, Ministry of Health and Medical Education, Tehran, IR Iran \\ "Corresponding author: Mashyaneh Haddadi, Safety Promotion and Injury Prevention Department, Ministry of Health and Medical Education, Tehran, IR Iran. E-mail: \\ mashyaneh_hd@yahoo.com
}

Received 2015 March 12; Revised 2016 January 17; Accepted 2016 January 30.

\begin{abstract}
Background: Motorcycle riders are amongst some of the most vulnerable road users. The burden of motorcycles injuries from low and middle income countries is under-reported.

Objectives: In this study, the cost of traffic injuries among motorcyclists was calculated using the willingness to pay (WTP) method in Iran in 2013.

Patients and Methods: In a cross-sectional study, 143 motorcyclists were randomly selected. The research questionnaire was prepared based on the standard WTP method [stated preference(SP), contingent value (CV) and revealed preference (RP) models] taking into consideration perceived risks, especially those in Iran. Data were collected by a scenario for motorcyclists. The criteria for inclusion in the study consisted of having at least a high school education and being in the age range of 18 - 65 years. The final analysis of the WTP data was performed using the Weibull model.

Results: The mean WTP was 888,110 IRR (Iranian Rial) among motorcyclists. The statistical value of life was estimated according to 4694 death cases as 3,146,225,350,943 IRR, which was equivalent to USD 104,874,178 based on the dollar free market rate of 30,000 IRR (purchasing power parity). The cost of injury was 6,903,839,551,000 IRR, equivalent to USD 230,127,985 (based upon 73,325 injured motorcyclists in 2013, a daily traffic volume of 311, and a daily payment of 12,110 IRR for 250 working days). In total, injury and death cases came to 10,050,094,901,943 IRR, equivalent to USD 335,003,163. Willingness to pay had a significant relationship with having experienced an accident, the length of the daily trip (in $\mathrm{km})$, and helmet use $(\mathrm{P}<0.001)$.

Conclusions: Willingness to pay can be affected by experiencing an accident, the distance of the daily trip, and helmet use. The cost of traffic injuries among motorcyclists shows that this rate is much higher than the global average. Thus, expenditure should be made on effective initiatives such as the safety of motorcyclists.
\end{abstract}

Keywords: Willingness to pay, Cost, Road Traffic Injury, Iran

\section{Background}

More than $90 \%$ of global deaths which occur on roads happen in low and middle-income countries, which together possess $48 \%$ of the world's registered vehicles (1). Traffic injuries with an annual occurrence rate of 26.5 cases per 100,000 people are the second highest cause of fatality and highest cause of lives lost in Iran. A global report on road safety in Iran in 2013 revealed that motorcyclists constituted $23 \%$ of all road traffic accident victims (2). Examining costs by the individual road user type has revealed that it would be rational to invest in initiatives to protect vulnerable road user groups. Motorcyclists are the most vulnerable road users. In Iran motorcycles are a major source of transportation and their usage has dramatically increased during recent years.
Miller showed that more injuries of a severe nature requiring rehabilitation occur among motorcyclists. Miller also emphasized that motorcycle helmet laws that are known to be cost-effective in terms of reducing motorcyclist injury and death and other related costs should be implemented (3). Bhalla et al. showed that analysis of hospital data illustrated that half of hospital admissions and outpatient visits were motorcyclists and that DALYs (disability adjusted life years) was highest for motorcycle riders (4).

Some studies have demonstrated that the use of helmets reduces the severity of head injuries and that a higher health care cost has been observed among non-helmet users (5-7) estimated the value of statistical life (VOSL) in comparison to other road users in 2010 among motorcyclists to be USD 0.14 million per fatality. Chaturabong et al. 
(8) determined the amount of money paid by each motorcycle user for reducing the risk of life loss due to motorcycle accidents. Their results showed that the value of statistical life and statistical injury was in the range of 5.5 million baht to 7.0 million baht ( 0.17 million to 0.21 million) and 2.6 million baht to 3.4 million baht ( 0.08 million to 0.10 million), respectively ( $\$ 1=32.5$ Thai baht in 2011). Age, gender, occupation, income, and helmet use were the significant factors affecting the motorcycle users' willingness to pay (WTP) in order to reduce the risk of fatality. Willingness to pay was less among motorcyclists than the other road users.

A few studies have been undertaken to calculate the cost of traffic injuries in Iran, each of which has used different methods. Most of these methods have used the human capital approach i.e. legal compensation. Generally speaking, the human capital approach suffers from underreporting (9). In contrast, the WTP method presents a more accurate illustration for estimating cost and is an appropriate way to increase social welfare by reducing injury and death (10-14). The WTP approach emphasizes the importance of individual preferences for risk changes and can be defined as the monetary measure of the value of a small reduction in the risk of death (15). The WTP may be alternatively defined as a compensating surplus measure for the sum of money that could be taken away from the individual who gains the mortality risks (16). There is no precise study on the cost of road traffic injuries to motorcyclists in Iran.

Researchers have attempted to observe accuracy in collecting the information for the required components of this method by basing the questionnaire on the global standards of the WTP method [contingent value (CV), stated preference (SP) and revealed preference (RP) models] considering perceived risks, especially in Iran, and then determining its validity and reliability.

\section{Objectives}

This study was the first one where the cost of traffic injuries among motorcyclists in a middle income country such as Iran was derived using the WTP method.

\section{Patients and Methods}

In a cross-sectional study on the costs resulting from traffic injuries, a global report on road safety was published for Iran (2), in which the proportions of pedestrians, two-wheeled motorcyclists, occupants of four-wheeled vehicles, and drivers of four-wheeled vehicles were $28 \%, 23 \%$, $26 \%$, and $23 \%$, respectively. In total, 640 road users were randomly selected based on these percentages from all road users in the city of Tehran. Findings from $23 \%$ of the road users (of which 147 were motorcyclists) are represented in this study.

Given that one of the key areas of focus in this research was with regard to risk perception, it was observed that 4 out of 147 people answered the questions incorrectly. This data was removed and the remaining data from 143 respondents were analyzed.

The research questionnaire was prepared based on the standard for the WTP method considering perceived risks, especially with respect to Iran. Validity was determined using content validity, which gained $75 \%$ of the overall degree of agreement out of 10 domain experts (by determining validity index and content validity ratio of 0.79 ). Its reliability was specified using the test-retest method as $r=0.88$. The questionnaire consisted of three parts:

In part 1, the revealed preference approach assumed that the value of a small mortality risk reduction can be inferred from the observable behavior. Examples included the choice of motorcycle type, the purchase and use of safety equipment (17).

In part 2, the stated preference survey method included a series of scenarios requiring people to make choices: the respondent motorcyclists were asked to make a choice between two identical helmets that differed only in price (high price equals more safety) and risk reduction.

In part 3, contingent value of mortality risk reduction from all causes is obtained via the direct question of how much they were willing to pay for road traffic injury reduction (18).

The questionnaire included various questions about the respondents such as main income earner, marital status, house ownership, willingness to donate via charity to injury reduction, willingness to pay for risk reduction, paying more for safety, paying more for saving time, paying more for fewer traffic hold ups, self-reported health (poor, average and good), trip mileage, road traffic injury history, helmet usage and fastening of the helmet strap.

A true indirect utility function can be obtained by using socio economic variables (19). So as a part of the study, behavioral modeling components such as the respondents' income, age, education, health status, family size, and personal vehicle were also obtained via the questionnaire.

In addition, the WTP approach was used to estimate the value of statistical life and cost of injuries. The criteria for inclusion in the study was having at least a high school education and being between 18 - 65 years of age. After a brief explanation about the study a consent letter was obtained from the subjects. For the implementation stage a briefing session was held for the interviewers to make them familiar with how to fill out the questionnaire and how to 
use the visual tool for assessing risk perception. The data collected were analyzed the following strict control procedure. The final analysis of WTP was carried out using the Weibull model and R software (ver. 2013-03-01, institute for statistics and mathematics, Vienna).

\subsection{Descriptive Illustration}

Figure 1 shows histograms of the WTP (left panel) and logarithm of WTP (right panel) for motorcycle users. This image illustrates that the observations are severely skewed. Panel (b) of this image demonstrates that some people had zero willingness to pay (these values were changed with the mean of 0 and 1000 (10,000 IRR) i.e. 500 (5,000 IRR) to calculate the logarithm of WTP) (Figure 1).
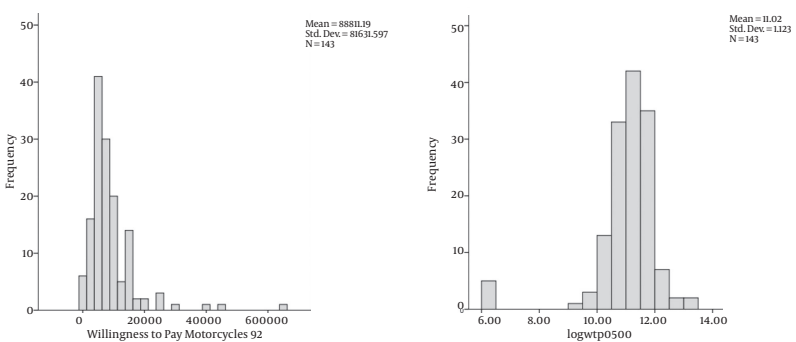

Figure 1. A, Histogram of willingness to pay (IRR) for motorcycle users; b, histogram of logarithm of willingness to pay (IRR) for motorcycle users.

\subsection{Statistical Model for Motorcycle Users}

The Weibull model was chosen because it has various graphics for different values of its parameters, is known to have a high flexibility and in the case of analyzing WTP, commonly delivers excellent results. Also, a plot of $\log (-\log$ $(1-\hat{F}($ WTP $))$ )versus $\log ($ WTP) where $\hat{F}($ WTP $)$ is the empirical distribution function of WTP showed us to have an almost straight line (20).

To establish WTP for motorcycle users, the Weibull model was used as follows:

$$
\begin{aligned}
\log \left(W_{i}\right) & =\mu_{i}+\varepsilon_{i}, i \\
& =1,2, \ldots, n
\end{aligned}
$$

Where $\mathrm{W}_{\mathrm{i}}$ is annual willingness to pay for the $\mathrm{i}^{\text {th }}$ person, $\epsilon_{\mathrm{i}}$ is the model error with extreme exponential distribution (which consequently leads to having a Weibull distribution for $\mathrm{W}_{\mathrm{i}}$ ) and

$$
\begin{aligned}
& \mu_{i}=\beta_{0}+\beta_{1} \operatorname{Ag}_{i}+\beta_{2} \operatorname{Ed} u_{i}+\beta_{3} \text { Familysize }_{1 i} \\
& +\beta_{4} \text { Familysize }_{2 i}+\beta_{5} \text { Income }_{1 i}+\beta_{6} \text { Income }_{2 i} \\
& +\beta_{7} \text { Accident }_{i}+\beta_{8} \log \left(\mathrm{Di}_{i}\right)+\beta_{9} \log \left(\mathrm{DPF}_{i}\right) \\
& +\beta_{10} \log \left(\mathrm{PT}_{i}\right)+\beta_{11} \text { Prefer64 }_{i} \\
& +\beta_{12} H 1_{i}+\beta_{13} H 2_{i}+\beta_{14} \text { Helmet }_{i} .
\end{aligned}
$$

\begin{tabular}{|c|c|c|c|}
\hline $\begin{array}{l}\text { Explanatory } \\
\text { Variable Name }\end{array}$ & Scale & $\begin{array}{c}\text { Number of } \\
\text { Levels }\end{array}$ & $\begin{array}{c}\text { Level's } \\
\text { Definition }\end{array}$ \\
\hline Age & Continuous & - & - \\
\hline \multirow[t]{2}{*}{ Edu (Education) } & Ordinal & 2 & Baseline: other \\
\hline & & - & $\begin{array}{c}\text { High school and } \\
12 \text { years } \\
\text { education }\end{array}$ \\
\hline \multirow[t]{3}{*}{ Family size } & Ordinal & 3 & Baseline: other \\
\hline & & - & $\begin{array}{c}\text { Family size1: } \\
\text { between } 1 \text { and } 4\end{array}$ \\
\hline & & - & $\begin{array}{l}\text { Family size } 2 \text { : } \\
\text { equal } 4\end{array}$ \\
\hline \multirow[t]{3}{*}{ Income } & Ordinal & 3 & Baseline: low \\
\hline & & - & $\begin{array}{l}\text { Income 1: } \\
\text { medium }\end{array}$ \\
\hline & & - & Income 2: high \\
\hline \multirow[t]{2}{*}{ Accident } & Binary & 2 & Baseline: others \\
\hline & & - & $\begin{array}{c}\text { Having an } \\
\text { accident } \\
\text { experience }\end{array}$ \\
\hline \multirow[t]{3}{*}{ H (Health) } & Ordinal & 3 & Baseline: high \\
\hline & & - & Health 1: low \\
\hline & & - & $\begin{array}{l}\text { Health 2: } \\
\text { medium }\end{array}$ \\
\hline $\log$ (Dis) & Continuous & - & - \\
\hline $\log$ (DPFR) & Continuous & - & - \\
\hline $\log ($ PTR $)$ & Continuous & - & - \\
\hline Prefer more pay & Continuous & - & - \\
\hline \multirow[t]{2}{*}{ Helmet } & Binary & 2 & $\begin{array}{l}\text { Baseline: not } \\
\text { using }\end{array}$ \\
\hline & & & Using \\
\hline
\end{tabular}

The following tabulation presents the names of explanatory variables, their recorded scale and possible categories (Table 1).

Table 1. Names of Explanatory Variables, Their Recorded Scale and Possible Categories

In this tabulation "Dis" represents the distance traveled by an individual ( $\mathrm{km})$, DPFR shows the daily payment for reducing injury risk, and PTR represents payment for travel time reduction and preference for paying more for less traffic. 


\subsection{Nature of the Likelihood Function}

The probability density function of the Weibull distribution with parameters $\lambda_{\mathrm{i}}$ and $\mathrm{r}$ is given by:

$f\left(w_{i} ; \lambda_{i}, r\right)=\lambda_{i} r w_{i}{ }^{r-1} \exp \left(-\lambda_{i} w_{i}{ }^{r}\right)$

Where $\lambda_{\mathrm{i}}$ is the scale parameter for the $\mathrm{i}^{\mathrm{th}}$ individual and $r$ is the shape parameter. In the Weibull regression model, $\lambda_{\mathrm{i}}$ is parameterized in terms of predictor variables and regression parameters (or $\mu_{\mathrm{i}}$ mentioned above) in the following way:

$\lambda_{i}=\exp \left(\mu_{i}\right)$

The mean of this model (mean WTP) is defined as follows:

$E\left[W_{i}\right]=\exp \left(\mu_{i}\right) \times \Gamma\left(1+\frac{1}{r}\right)$.

Therefore, the observed likelihood function is as follows:

$$
\begin{aligned}
L(\beta, r w) & =\prod_{i=1}^{n} f\left(w_{i} ; \lambda_{i}, r\right) \\
& =\prod_{i=1}^{n}\left(\lambda_{i} r w_{i}{ }^{r-1} \exp \left(-\lambda_{i} w_{i}{ }^{r}\right)\right)
\end{aligned}
$$

Where $\mathrm{f}\left(. ; \lambda_{\mathrm{i}}, \mathrm{r}\right)$ denotes the density function of the Weibull model with shape parameter $\mathrm{r}$ and scale parameter $\lambda_{\mathrm{i}}$.

\subsection{Presence of Participants With Zero Willingness to Pay: Ap-} proaches and Likelihood

One problem in the analysis of the above-mentioned data is the existence of 5 zeroes in the values of the WTP variable. Two solutions exist for this problem. The first method is to replace the zero values with the midpoint of 0 and 1000 (10,000 IRR), i.e. 500 (5,000 IRR). If an indicator variable is defined as follows:

$$
Z_{i}=\left\{\begin{array}{c}
1, \text { zero willingness to pay } \\
0, \text { o.w }
\end{array}\right.
$$

The likelihood function is as follows (assuming $\mathrm{n}$ as the total number of drivers):

$$
\begin{aligned}
L(\beta, r w)= & \prod_{i=1}^{n}\left(\mathrm{f}\left(w_{i} ; \lambda_{i}, r\right)\right)^{1-z_{i}} \times\left(\mathrm{f}\left(500 ; \lambda_{i}, r\right)\right)^{z_{i}} \\
= & \prod_{i=1}^{n}\left\{\left(\lambda_{i} r w_{i}{ }^{r-1} \exp \left(-\lambda_{i} w_{i}{ }^{r}\right)\right)^{1-z_{i}}\right. \\
& \left.\times\left(\lambda_{i} r 500^{r-1} \exp \left(-\lambda_{i} 500^{r}\right)\right)^{z_{i}}\right\}
\end{aligned}
$$

Where $\mathrm{z}_{\mathrm{i}}$ is the observed value of $\mathrm{Z}_{\mathrm{i}}$.

The second approach for dealing with the zero values is to assume that these respondents' WTP was less than the minimum value in the sample 1000 (10,000 IRR). In this case, the likelihood function is as follows (assuming $\mathrm{n}$ as the total number of drivers):

$$
\begin{array}{r}
L(\beta, r w)=\prod_{i=1}^{n}\left(\mathrm{f}\left(w_{i} ; \lambda_{i}, r\right)\right)^{1-z_{i}} \times\left(\mathrm{F}\left(1000 ; \lambda_{i}, r\right)\right)^{z_{i}} \\
=\prod_{i=1}^{n}\left\{\left(\lambda_{i} r w_{i}{ }^{r-1} \exp [\mathrm{U}+2061]\left(-\lambda_{i} w_{i}{ }^{r}\right)\right)^{1-z_{i}}\right. \\
\left.\times\left(\exp \left(-\lambda_{i}(1000)^{r}\right)\right)^{z_{i}}\right\}
\end{array}
$$

Where $F(1000)$ (10,000IRR) is the cumulative distribution function of Weibull evaluated at 1000 (10,000IRR).

\section{Results}

The mean age of the respondents was 31.4 years (SD $=7.9$ ). All the subjects were men and $57.3 \%$ of the studied population was married. The mean family size was 4.31 and $66.4 \%$ of the respondents were the main income earners. Employment status showed that the highest proportion of respondents (67.8\%) was self-employed, $48.3 \%$ owned houses, and $98.6 \%$ owned motorcycles. Educational status revealed that most of the respondents had reached 1 (59.4\%). In addition, the majority of respondents had a monthly income of between 5 and 10 million IRR (49\%).

In terms of trip purpose, the main activity was for business (85.3\%). Most of the respondents left and returned home in the morning (97.2\%) and 61.2\% returned home at night or by midnight. Amongst these motorcyclists, the mean WTP was 888,110 IRR. Helmet usage was $89.5 \%$ and $48.2 \%$ of the respondents fastened the helmet strap. Results showed that the high-risk road user motorcyclists constituted the highest percentage (62.9\%) in this regard.

\subsection{Estimation of the Cost of Fatalities}

Actual risk of death from traffic injuries in Iran is approximately 26.5 per 100,000 road users; therefore, a 50\% reduction in risk equates to a reduction of 13.25 injuries per 100,000 people. To obtain the value of statistical life, the CV value (888,110 IRR) was multiplied by 100,000/13.25. The statistical value of life was estimated according to 4694 incidents of death amongst motorcyclists (as estimated by the 2013 Legal Forensic of Iran (LFI)) 3,146,225,350,943 IRR, equivalent to USD 104,875,178 based on the dollar free market rate of 30,000 IRR (purchasing power parity).

The estimated value of the avoidance of serious injury was $6,903,839,551,000$ IRR, equivalent to USD $230,127,985$, which is based upon 73,325 cases of motorcyclist injuries (by the 2013 legal forensic of Iran (LFI)) multiplied by the daily traffic volume of 311 (estimated by the 2013 road maintenance and transportation organization, ministry of road and urban development of Iran) multiplied by a daily payment of 12,110 IRR for 250 working days). 
To summarize, injury and death cases came to 10,050,094,901,943 IRR, equivalent to USD 335,003,163.

Table 2 shows the components of contingent value among respondents. Means of monthly income and daily payment were the highest and lowest rates, respectively.

Table 3 demonstrates the maximum likelihood estimates using a value less than 1000 (10,000 IRR) for zero values. These results are considered all complete observed covariates $(\mathrm{n}=70)$ in motorcyclists, which showed that WTP had a significant relationship with experience of an accident and the length (in $\mathrm{km}$ ) of the daily trip.

In this tabulation log (shape parameter) is the logarithm of the shape parameter defined in Equation 1. However, as the number of complete observations was low it was more reasonable to impute the missing values and fit the model with all 143 observations. Table 4 provides the results of the maximum likelihood approach using a value less than 500 (5,000 IRR) for zero values and a regression imputation for missing covariates values (little and Rubin, 2002) among motorcyclists. This demonstrated that WTP was significantly related to the length (in $\mathrm{km}$ ) of the daily trip and helmet use.

\section{Discussion}

Results showed that value of statistical life for a death case was 670,271,698 IRR. Willingness to pay was higher among those who had experienced an accident, had a short daily trip (in $\mathrm{km}$ ), and used a helmet. More than fourfifths of the respondents traveled for business purposes while the remainder traveled for educational or other purposes. Most studies have demonstrated that motorcyclists have $25 \%$ to $50 \%$ more WTP for a reduction in delay to their journey (21). Lindberg et al.'s findings demonstrated that a light vehicle such as motorcycle could be more dangerous for its own passenger, while heavy vehicles like buses are more dangerous for nonpassengers, which are considered external costs. Although accident risk is different in various modes, the pattern is the same for passengers and nonpassengers. Willingness to pay is a proper method for calculating value of statistical life (22). According to the results of this study, it seems that this group of users either has poor risk perception because of their lack of knowledge about potential hazards of this vehicle due to its inherent safety risks, or is obliged to use it due to their low monthly income. Other studies have demonstrated that motorcyclists are willing to reduce their trip time, which increases the risk rate due to higher speed and thus increases the probability of them being injured. People who use motorcycle helmets are more willing to pay. Also, motorcyclists who travel a shorter route are more willing to pay. It seems that motorcyclists prefer shorter routes in order to enjoy better services. Motorcyclists who use helmets probably have a better risk perception and as a result they have more willingness to pay. In line with this study's findings, a number of other works have found similar results (5, 6, 23-25). Brandt et al.'s findings demonstrated that mortality from head injuries was reduced among helmet users (26). In theoretical terms, WTP is a proper method for determining cost of injuries; it is conceptually correct and provides a better reflection from the social value of safety (26). This study provided a road traffic injury cost by one road user group (i.e. motorcyclists). A combination of strategies such as the joint enforcement of motorcycle helmet use and limitation on kilometer daily trip for each motorcyclist, especially among those with a road traffic injury experience, helps identify the best value for money investment. In the present study, the estimate of USD 335,003,163 was substantially greater than most other published estimates. This latest cost estimation has highlighted the need for urgent legislation for motorcycle helmet use and for considering the introduction of government subsidies to encourage better quality helmet use.

The use of the three methods of contingent valuation, stated preference, and revealed preference can be considered as the innovation of this study. In none of the previous works have these three methods have been used simultaneously. The Weibull models in these instances were only used for modeling WTP. In this study the regression imputation method was applied for imputing missing covariates values. In similar studies, missing values and the way of dealing with them have not been described. This measurement is an innovation in the accurate calculation of costs of traffic injuries. The small sample size could be considered as a limitation of the study.

\subsection{Conclusion}

Willingness to pay is affected by having experienced an accident, the length of the daily trip (in km) and helmet usage. The cost of traffic injuries among motorcyclists revealed that this rate was much higher than the global average. In the case of the latter, it seems that effective investments must have been made in fields such as safety for motorcyclists. Considering social equality, road users with low incomes need to receive more attention with regard to road traffic injury reduction.

\section{Acknowledgments}

Financial support of traffic police(Rahvar research center) is appreciated. Also, we want to acknowledge scientific advice of Dr. Soad Mahfouzpour, Dr. Ali Montazeri and cooperation of all the colleagues in safety promotion and in- 
Table 2. Components of Contingent Value Among Motorcyclists $(\mathrm{N}=143)$

\begin{tabular}{|c|c|c|c|c|c|}
\hline Variables (per IRR) & Mean \pm SD & Min & Max & Median & Mode \\
\hline Daily payment (charity) & $12,110 \pm 11,770$ & 1,000 & 50,000 & 10,000 & 10,000 \\
\hline Risk reduction $\mathbf{5 0} \%$ & $453,480 \pm 621,820$ & 0 & $7,000,000$ & $5,000,000$ & 0 \\
\hline Willingness to pay & $888,110 \pm 816,320$ & 0 & $6,500,000$ & 700,000 & 500,000 \\
\hline Monthly income & $12,238,000 \pm 3,064,930$ & $5,000,000$ & $20,000,000$ & $10,000,000$ & $10,000,000$ \\
\hline
\end{tabular}

Abbreviations: Max, maximum; Min, minimum; SD, standard deviation.

Table 3. Results of Maximum Likelihood Using a Value Less Than 1000 (10,000 IRR) for Zero Values for Complete Observed Data ( $\mathrm{N}=70$ )

\begin{tabular}{|c|c|c|c|c|}
\hline \multirow[t]{2}{*}{ Variable } & \multicolumn{4}{|c|}{ Observed } \\
\hline & Est. & S.E & Z-Value & P-Value \\
\hline Intercept & 14.7534 & 1.4097 & 10.466 & $<0.001$ \\
\hline Age & 0.0054 & 0.0118 & 0.457 & NS \\
\hline Education (high school and 12 years education) & 0.03 & 0.2503 & 0.12 & NS \\
\hline Family size & & & & NS \\
\hline Less than 4 & -0.1117 & 0.2337 & -0.478 & NS \\
\hline Equal to 4 & 0.0756 & 0.2381 & 0.318 & \\
\hline \multicolumn{5}{|l|}{ Income } \\
\hline Middle income & 0.4374 & 0.3717 & 1.177 & NS \\
\hline High income & 0.2405 & 0.8062 & 0.298 & NS \\
\hline Has an accident experience ${ }^{a}$ & -0.5381 & 0.1759 & -3.06 & $<0.001$ \\
\hline Log (kilometer moving) ${ }^{\mathbf{a}}$ & -0.5332 & 0.1659 & -3.215 & $<0.001$ \\
\hline Log (daily payment to fatal reduction) & -0.094 & 0.0896 & -1.049 & NS \\
\hline Log (pay to time reduction) & -0.0409 & 0.0353 & -1.159 & NS \\
\hline Prefer to more pay to less traffic & -0.0468 & 0.213 & -0.22 & NS \\
\hline \multicolumn{5}{|l|}{ Health } \\
\hline Low & 0.3649 & 0.4357 & 0.837 & NS \\
\hline Middle & 0.553 & 0.4327 & 1.278 & NS \\
\hline Helmet using & -0.486 & 0.3871 & -1.256 & NS \\
\hline Log (shape parameter) & -0.4743 & 0.0919 & -5.163 & $<0.001$ \\
\hline Log likelihood & \multicolumn{4}{|c|}{-856.5} \\
\hline
\end{tabular}

Abbreviation: NS, not significant.

${ }^{\mathrm{a}}$ Significant covariates.

jury prevention research center. We would also thank Mr. David Mallinson for English editing.

\section{Footnotes}

Authors' Contribution: Elaheh Ainy: design, monitoring data gathering, analysis and manuscript writing; Hamid Soori: design, monitoring data gathering, analysis and manuscript writing; Mojtaba Ganjali: analy- sis and manuscript writing; Behzad Basirat: design and manuscript writing; Mashyaneh Haddadi: design, monitoring data gathering, analysis and manuscript writing.

Funding/Support: Financial support of traffic police (Rahvar research center).

\section{References}

1. Mathers CD, Boerma T, Ma Fat D. Global and regional causes of 
Table 4. Results of Maximum Likelihood Using a Value Less Than 500 (5,000 Irr) for Zero Values and Regression Imputation for Missing Values Among Motorcyclists; Observed Data $(\mathrm{N}=143)$

\begin{tabular}{|c|c|c|c|c|c|c|c|c|}
\hline \multirow[t]{3}{*}{ Variable } & \multicolumn{8}{|c|}{ Regression Imputation } \\
\hline & \multicolumn{4}{|c|}{500} & \multicolumn{4}{|c|}{ Left Censored } \\
\hline & Est. & S.E & Z-Value & P-Value & Est. & S.E & Z-Value & P-Value \\
\hline Intercept & 13.16579 & 1.01448 & 12.978 & $\mathrm{P}<0.001$ & 13.16473 & 1.0156 & 12.963 & $\mathrm{P}<0.001$ \\
\hline Age & -0.00226 & 0.00869 & -0.261 & NS & -0.00225 & 0.0087 & -0.259 & NS \\
\hline \multicolumn{9}{|l|}{ Family size } \\
\hline Less than 4 & 0.11251 & 0.17693 & 0.636 & NS & 0.11231 & 0.1771 & NS & NS \\
\hline Equal to 4 & 0.13577 & 0.18078 & 0.751 & NS & 0.13569 & 0.181 & 0.75 & NS \\
\hline \multicolumn{9}{|l|}{ Income } \\
\hline Middle & 0.41153 & 0.33335 & 1.235 & NS & 0.41127 & 0.3337 & 1.232 & NS \\
\hline High & 0.16975 & 0.58364 & 0.291 & NS & 0.16976 & 0.5843 & 0.291 & NS \\
\hline Has had an accident experience & -0.12763 & 0.14231 & -0.897 & NS & -0.12757 & 0.1425 & -0.895 & \\
\hline Log (kilometer moving) $)^{a}$ & -0.29447 & 0.12477 & -2.36 & $\mathrm{P}<0.01$ & -0.29439 & 0.1249 & -2.357 & $\mathrm{P}<0.01$ \\
\hline Log (daily payment to fatal reduction) & 0.00897 & 0.07452 & 0.12 & NS & 0.00898 & 0.0746 & 0.12 & NS \\
\hline Log (pay to time reduction) & -0.04465 & 0.03803 & -1.174 & NS & -0.04462 & 0.0381 & -1.172 & NS \\
\hline Prefer to pay more to less traffic & -0.13304 & 0.13126 & -1.014 & NS & -0.13294 & 0.1314 & -1.012 & NS \\
\hline \multicolumn{9}{|l|}{ Health } \\
\hline Low & 0.43126 & 0.27881 & 1.547 & NS & 0.4311 & 0.2791 & NS & NS \\
\hline Middle & 0.39745 & 0.27869 & 1.426 & NS & 0.39734 & 0.279 & NS & NS \\
\hline Helmet using ${ }^{a}$ & -0.80213 & 0.22511 & -3.563 & $\mathrm{P}<0.001$ & -0.80203 & 0.2253 & -3.559 & $\mathrm{P}<0.001$ \\
\hline Log (shape parameter) & -0.30963 & 0.06355 & -4.872 & $\mathrm{P}<0.001$ & -0.30853 & 0.0642 & -4.803 & $\mathrm{P}<0.001$ \\
\hline
\end{tabular}

Abbreviation: NS, not significant.

${ }^{\mathrm{a}}$ Significant covariates.

death. Br Med Bull. 2009;92:7-32. doi: 10.1093/bmb/ldp028. [PubMed: 19776034].

2. World Health Organization. Global status report on road safety: time for action. World Health Organization; 2009.

3. Miller TR, Finkelstein AE, Zaloshnja E, Hendrie D. The cost of child and adolescent injuries and the savings from prevention. Injury prevention for children and adolescents: Research, practice and advocacy. 2006:1565.

4. Bhalla K, Naghavi M, Shahraz S, Bartels D, Murray CJ. Building national estimates of the burden of road traffic injuries in developing countries from all available data sources: Iran. Inj Prev. 2009;15(3):150-6. doi: 10.1136/ip.2008.020826. [PubMed:19494093].

5. Kelly P, Sanson T, Strange G, Orsay E. A prospective study of the impact of helmet usage on motorcycle trauma. Annal emerg Med. 1991;20(8):852-6.

6. Eastridge BJ, Shafi S, Minei JP, Culica D, McConnel C, Gentilello L. Economic impact of motorcycle helmets: from impact to discharge. J Trauma. 2006;60(5):978-83. doi: 10.1097/01.ta.0000215582.86115.01. [PubMed: 16688058] discussion 983-4.

7. Yusof M, Mohamad N, Faudzi M, editors. The Malaysian value of reducing fatal and non fatal injuries due to road accidents: a willingness to pay study using conjoint analysis approach. Proceedings of the road safety on four continents conference. 2010; Conference Sponsor; pp.
1240-52.

8. Chaturabong P, Kanitpong K, Jiwattanakulpaisarn P. Analysis of Costs of Motorcycle Accidents in Thailand by Willingness-to-Pay Method. Transp Res Rec. 2011(2239):56-63.

9. Ministry of Science. The cost of suburban and inner city road traffic injuries (Theory and application) [in Persian]. 2012

10. Wang Y, Guo Z. Road safety evaluation based on fuzzy logic. Tongji Univ. 2008;36(1):47.

11. Downing AJ, Baguley CJ, Hills BL, editors. Road safety in developing countries: an overview. The nineteenth transport, highways and planning summer annual meeting, university of sussex, brighton. 1991; .

12. Downing A, editor. Accident costs in Indonesia: A review. International Conference on Road Safety, Andhra University, Visakhapatnam, India. 1997;

13. Al-Masaeid HR, Al-Mashakbeh AA, Qudah AM. Economic costs of traffic accidents in Jordan. Accid Anal Prev. 1999;31(4):347-57.

14. Jarawan E, Mohan D, Hyder AA, Peden M, Scurfiled R, Sleet D. World report on road traffic injury prevention. 2004

15. Freeman III AM, Herriges JA, Kling CL. The measurement of environmental and resource values: theory and methods. Routledge; 2014.

16. Schelling T. The life you save may be your own. ; 1968 .

17. Blomquist GC. Self-protection and averting behavior, values of statis- 
tical lives, and benefit cost analysis of environmental policy. Rev Econ Househ. 2004;2(1):89-110.

18. Bhattacharya S, Alberini A, Cropper ML. The value of mortality risk reductions in Delhi, India. J Risk Uncertain. 2007;34(1):21-47.

19. Gururaj G. Road traffic deaths, injuries and disabilities in India: current scenario. Natl Med J India. 2008;21(1):14-20. [PubMed: 18472698].

20. Nelson WB. Applied life data analysis. 577. John Wiley and Sons; 2005.

21. Antoniou C. A stated-preference study of the willingness-to-pay to reduce traffic risk in urban vs. rural roads. Euro Trans Res Rev. 2014;6(1):31-42.

22. Lindberg G. Calculating transport accident costs: Final report of the expert advisors to the high level group on infrastructure charging. Swedish national road and transport research institute (vti); 1999.
23. Oluwadiya KS, Oginni LM, Olasinde AA, Fadiora SO. Motorcycle limb injuries in a developing country. West Afr J Med. 2004;23(1):42-7. [PubMed: 15171525].

24. Asogwa SE. Some characteristics of drivers and riders involved in road traffic accidents in Nigeria. East Afr Med J. 1980;57(6):399-404. [PubMed: 7398556].

25. Keng SH. Helmet use and motorcycle fatalities in Taiwan. Accid Anal Prev. 2005;37(2):349-55. doi: 10.1016/j.aap.2004.09.006. [PubMed: 15667822].

26. Brandt MM, Ahrns KS, Corpron CA, Franklin GA, Wahl WL. Hospital cost is reduced by motorcycle helmet use. J Trauma Acute Care Surg. 2002;53(3):469-71. 